\title{
Changes in Plasma Amino Acids During the Oral Glucose Tolerance Test and the Effect of these Changes on Hepatic Encephalopathy
}

\author{
By Yasuyo Hijikata, Yasuko Shiozaki and Yoshiko Sameshima \\ The 3rd Department of Internal Medicine, Kansai Medical University, Moriguchi, Osaka, Japan
}

(Received July 19/November 5, 1984))

\begin{abstract}
Summary: Changes in amino acid concentrations in plasma during a $100 \mathrm{~g}$ oral glucose tolerance test were investigated in patients with liver cirrhosis and in healthy controls. In the controls, almost all amino acid concentrations reached a nadir about 3 hours after glucose loading, then returned to initial levels after 6 hours. Immunoreactive insulin levels reached a peak about 30 minutes after loading, then decreased gradually, reaching initial levels after 6 hours. In the controls, the decrease ratios, defined as maximum decrease during the 3 hours after loading/initial concentration in plasma, were 0.607 and 0.554 for isoleucine (Ile) and leucine (Leu) respectively and $\mathbf{0 . 3 8 2}$ for valine (Val) which is significantly lower than for Ile or Leu. A similar tendency was recognized in patients with liver cirrhosis. The initial concentration of tyrosine (Tyr) and phenylalanine (Phe) in liver cirrhosis was significantly higher and their decrease ratios were significantly lower than in controls. Though no difference was observed between initial concentrations of tryptophan (Trp) in controls and liver cirrhosis patients, the decrease ratio of $\operatorname{Trp}$ in liver cirrhosis was lower $(0.061)$ than that of controls $(0.279)(p<0.001)$.

The value, $t-\operatorname{Trp} / \mathrm{BCAA}+\mathrm{AAA}$, i. e. total Trp concentration $(\mathrm{mmol} / \mathrm{l}) /$ concentration $(\mathrm{mmol} / \mathrm{l})$ of branched chain amino acids (BCAA, Ile + Leu + Val) plus aromatic amino acids (AAA, Tyr + Phe), which is known to correlate with the brain Trp concentration of rats (Fernstrom, J. D. \& Wurtman, R. J. (1972) Science 178, 414-416), changed significantly from $9.6 \pm 2.4$ (mean $\pm 1 \mathrm{SD}$ ) at the initiation to $12.9 \pm 3.3$ at 3 hours after loading in controls $(p<0.001$ ), and in liver cirrhosis it changed from $10.3 \pm 1.9$ to $15.8 \pm 3.1$ (p $<0.001)$. The net increase of the value $t-T r p / B C A A+A A A$ during the 3 hours in liver cirrhosis $(0.055 \pm$ $0.026)$ was significantly higher than in controls $(0.031 \pm 0.021),(p<0.02)$. The value BCAA/AAA in controls did not change following glucose loading, but in liver cirrhosis it decreased from 1.4 to 1.0.
\end{abstract}

Änderungen der Konzentration der Aminosäuren im Plasma während des oralen Glucosetoleranztests und ihre Wirkung auf die hepatische Encephalopathie

Zusammenfassung: Die Änderungen der Konzentration der Aminosäuren im Plasma während eines oralen Glucosetoleranztests mit $100 \mathrm{~g}$ Glucose wurden bei Patienten mit Lebercirrhose und bei gesunden Kontrollpersonen untersucht. Bei den Kontrollpersonen erreichten fast alle Aminosäuren ihre geringste Konzentration etwa $3 \mathrm{~h}$ nach Glucosebelastung und zeigten nach $6 \mathrm{~h}$ wieder ihre Ausgangskonzentrationen.

Das immunreaktive Insulin erreichte einen Spitzenwert etwa $30 \mathrm{~min}$ nach Glucosebelastung, fiel dann allmählich $\mathrm{ab}$ und hatte nach $6 \mathrm{~h}$ die Ausgangskonzentration wieder erreicht.

Die maximale Konzentrationsdifferenz der Aminosäuren im Plasma während der $3 \mathrm{~h}$ nach Glucosebelastung wurde als Fraktion der Ausgangskonżentration berechnet. Dieser Quotient betrug bei den Kontrollpersonen 0,607 für Isoleucin und 0,554 für Leucin; er war für Valin mit 0,382 signifikant geringer. Eine ähnliche Tendenz zeigten Patienten mit Lebercirrhose. Die Ausgangskonzentrationen von Tyrosin und Phenylalanin waren bei Patienten mit Lebercirrhose signifikant höher und ihre Verringerung war signifikant geringer als 
bei den Kontrollpersonen. Obwohl sich die Ausgangskonzentrationen von Tryptophan nicht unterschieden, war die Verringerung der Konzentration bei Patienten mit Lebercirrhose geringer; der Quotient betrug 0,061 gegenüber 0,279 bei den Kontrollpersonen ( $p<0,001$ ).

Der Quotient aus der millimolaren Konzentration des Gesamttryptophans und der Summe der millimolaren Konzentrationen der verzweigtkettigen und aromatischen Aminosäuren, der mit der Tryptophankonzentration im Gehirn von Ratten korreliert (Fernstrom, J. D. \& Wurtman, R. J. (1972) Science 178; 414-416), änderte sich bei den Kontrollpersonen signifikant von 9,6 $\pm 2,4(\bar{x} \pm \mathrm{s})$ zu Beginn auf 12,9 $\pm 3,3(\mathrm{p}<0.001) 3 \mathrm{~h}$ nach Glucosebelastung, bei den Patienten mit Lebercirrhose signifikant von 10,3 \pm 1,9 auf 15,8 $\pm 3,1$ (p $<0,001)$. Der Nettoanstieg dieses Konzentrationsquotienten während der $3 \mathrm{~h}$ nach Glucosebelastung war bei den Patienten mit Lebercirrhose $(0,055 \pm 0,026)$ signifikant $(p<0,02)$ höher als bei den Kontrollpersonen $(0,031 \pm 0,021)$.

Der Quotient aus den millimolaren Konzentrationen aus verzweigtkettigen und aromatischen Aminosäuren änderte sich nach Glucosebelastung bei den Kontrollpersonen nicht, er fiel jedoch bei den Patienten mit Lebercirrhose von 1,4 auf 1,0 .

\section{Introduction}

Plasma tryptophan is often taken into consideration in hepatic encephalopathy. In some cases of hepatic encephalopathy, uptake of tryptophan into the brain increases, followed by an increase of serotonin, 5-hydroxyindole acetic acid and various pseudoneurotransmitters (2.3).

Fernstrom et al. (4) reported that plasma free tryptophan (f-Trp) did not correlate with brain tryptophan in rat but total Trp/branched chain amino acids + aromatic amino acids (t-Trp/BCAA + AAA) correlated strongly with brain tryptophan. These authors also discussed the relation between brain tryptophan and diurnal variations in plasma amino acids of patients with liver cirrhosis and healthy controls fed on protein, carbohydrate and mixed diets (4). We previously reported that plasma free tryptophan did not correlate with hepatic encephalopathy (5).

This study was designed to obtain information concerning preventive foods for hepatic encephalopathy. Instead of examining diurnal variations in plasma amino acids during consumption of carbohydrate, which is the main constituent in a Japanese diet, we studied changes of plasma amino acid concentrations, mainly branched chain amino acids and aromatic amino acids, during an oral glucose tolerance test in patients with liver cirrhosis and in healthy controls.

\section{Materials and Methods \\ Patients}

Nine healthy male and seven female volunteers ranging from 23 to 42 years old and eleven male and seven females with compensated liver cirrhosis ranging from 42 to 72 years old were studied. The diagnosis was based on clinical and laboratory data and on laparoscopy and/or biopsy.

\section{Oral glucose tolerance test}

$100 \mathrm{~g}$ of glucose was administered orally after an overnight fast to controls and patients. Blood was drawn at $0,0.5,1,2,3$, hours after loading from the antecuvital vein, and analysed for glucose, insulin and glucagon levels. Plasma amino acid was also assayed (7). In controls, assays were continued up to 6 hours.

Indocyanine green test

Indocyanine green test was carried out on patients with chronic hepatitis (15), liver cirrhosis (14) and liver cancer (3) while in a state of fasting.

Assay procedures

Immunoreactive insulin (IRI) levels were measured by a double antibody technique (Dainabot). Immunoreactive glucagon (IRG) was determined by radioimmunoassay using Unger's $30 \mathrm{~K}$ antibody. IRI/IRG was calculated as suggested by Muller et al. (6) using the following formula: IRI/IRG = IRI (mU//l)/ $\operatorname{IRG}(\mathrm{ng} / \mathrm{l}) \times 23.33$.

The plasma glucose concentration was determined by the hexokinase method.

Plasma amino acids were assayed by high performance liquid chromatography (Shimazu Corp., Kyoto) using a column filled with styrene divinylbenzene polymer sulfonated cationexchange resin (7). Details of tryptophan assay were also reported previously (8).

\section{Results}

\section{Changes in plasma glucose, insulin and glucagon}

Figures 1 and 2 show changes in plasma glucose, immunoreactive insulin (IRI), immunoreactive glucagon (IRG) and IRI/IRG during the oral glucose tolerance test in patients with liver cirrhosis and in healthy controls. In the controls plasima glucose and immunoreactive insulin were maximal after $30 \mathrm{~min}$ utes, followed by a gradual decrease, reaching the basal level at 6 hours after loading. Immunoreactive glucagon decreased during the fịrst hour aftẹ loading 

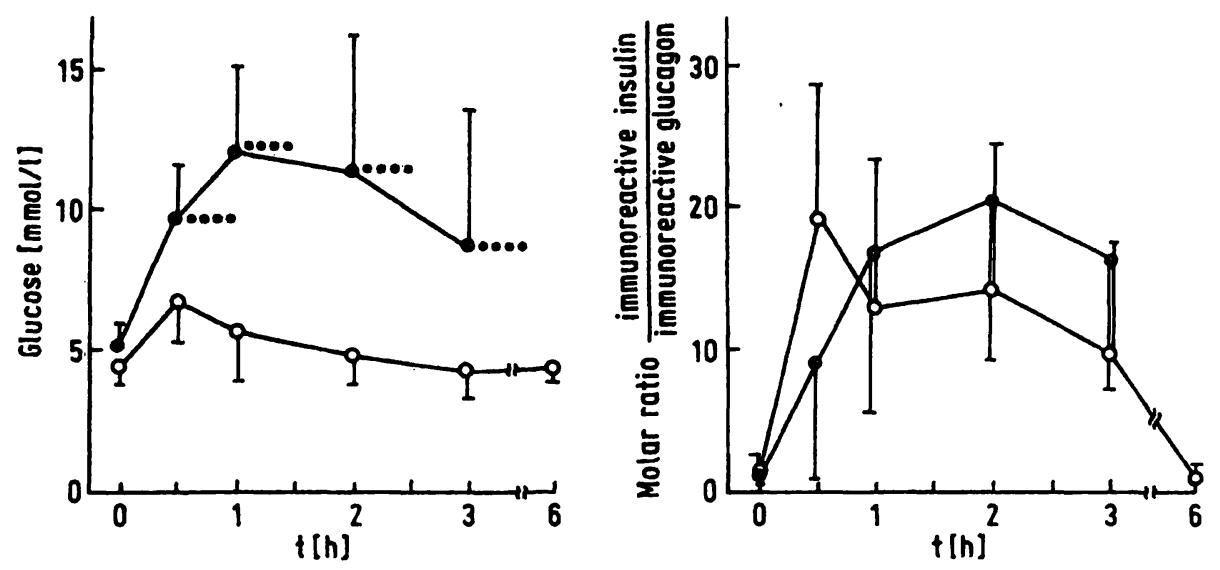

Fig. 1. Changes in plasma glucose and molar ratio of immunoreactive insulin/immunoreactive glucagon during a $100 \mathrm{~g}$ oral glucose tolerance test in patients with liver cirrhosis $(\Theta, n=18)$ and in normal control $(O, n=16)$. The marks show significant differences from control: $* * * * p<0.001$.
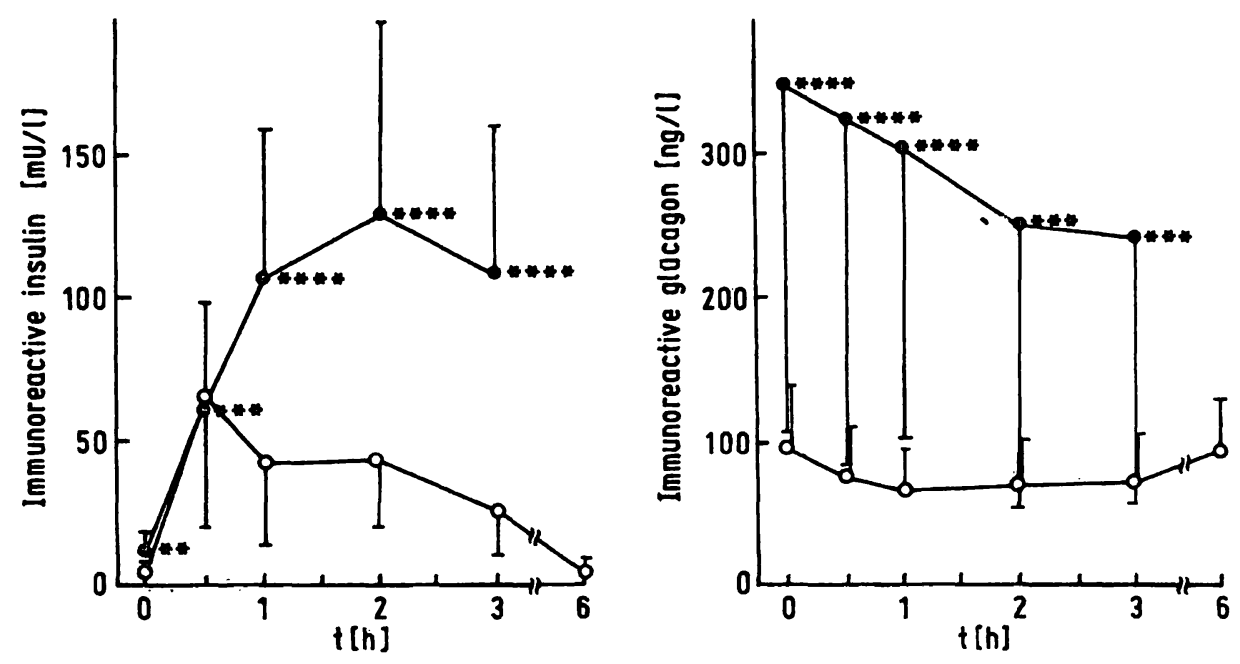

Fig. 2. Changes in plasma immunoreactive insulin and glucagon during a $100 \mathrm{~g}$ oral glucose tolerance test in patients with liver cirrhosis (O) and in normal control $(O)$. The marks show significant differences from control: $* * p<0.02, * * * p<0.01$, $* * * * \mathrm{p}<0.001$.

and then gradually recovered. Compared with controls, patients with liver cirrhosis showed the more marked and prolonged hyperglycaemia and relative hyperinsulinism after oral glucose tolerance test.

\section{Changes in plasma amino acids concentrations during oral glucose tolerance test}

Changes in plasma branched chain amino acids (BCAA) and aromatic amino acids (AAA) in controls during oral glucose tolerance test is shown in figure 3. Issoleucine (Ile) and leucine (Leu) decreased, being minimal about 3 hours after loading and nearly regaining their original levels at 6 hours. However, valine (Val), which was one of the branched chain amino acids tested, decreased at a significantly lower rate and its pattern of change differed from those of isoleucine and leucine (tab. 1). Tyrosine (Tyr) and phenylalanine ( $\mathrm{Phe}$ ) were found to change in a similar pattern (fig. 3). However tryptophan did not decrease as much as tyrosine and phenylalanine (tab.1). Almost all amino acids including those not shown here reached a nadir at 3 hours after loading.

The decrease ratio and the initial concentrations are listed in table 1. The initial concentrations of branched chain amino acids in patients with liver cirrhosis were significantly lower and tyrosine and phenylalanine were higher than in controls. The decrease ratio of isoleucine and leucine were higher, and those of tryptophan, tyrosine and phenylalanine were lower in patients with liver cirrhosis than in controls. 


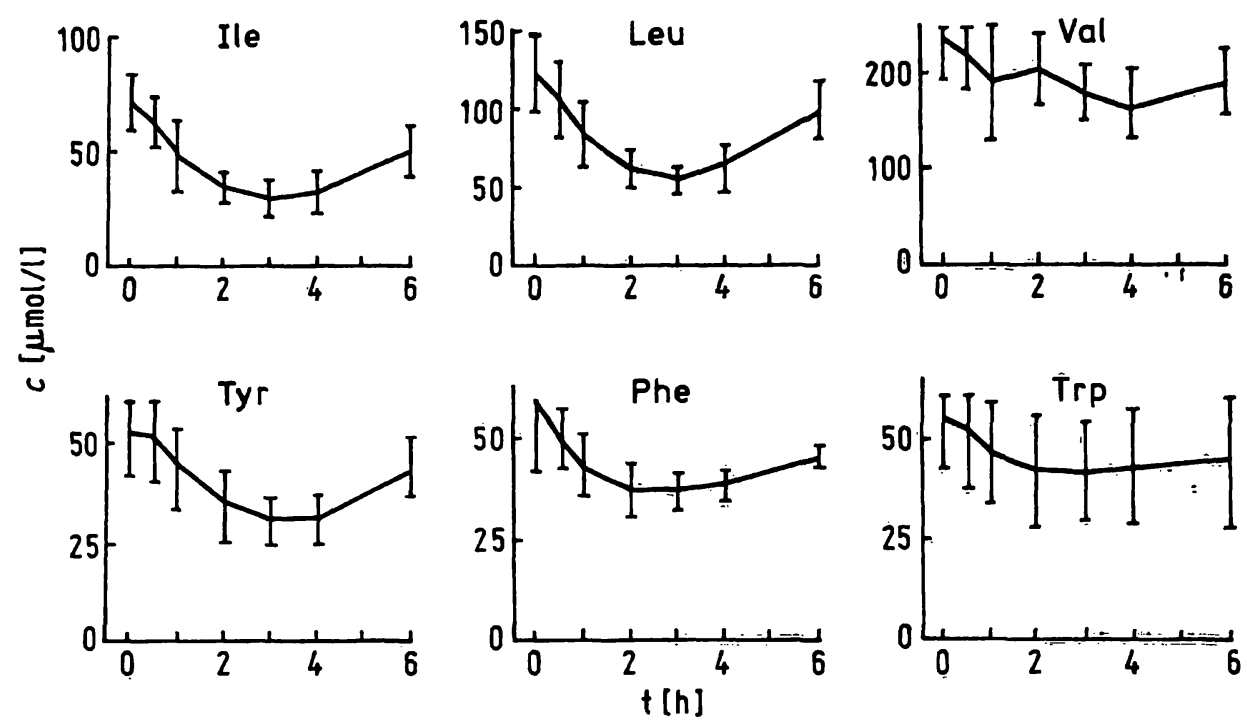

Fig. 3. Changes in branched chain amino acids (BCAA), aromatic amino acids (AAA) and tryptophan in healthy control during $100 \mathrm{~g}$ oral glucose tolerance test.

Tab. 1. Concentrations and decrease ratio of plasma amino acids during a $100 \mathrm{~g}$ oral glucose tolerance test in normal controls and in patients with liver cirrhosis.

\begin{tabular}{lrrrrrr}
\hline \multicolumn{3}{l}{$\begin{array}{l}\text { Concentration }(\mu \mathrm{mol} / \mathrm{l}) \text { at } \\
\text { Initial }\end{array}$} & \multicolumn{2}{l}{$\begin{array}{l}\text { Decrease ratio } \\
\text { Control }\end{array}$} & Liver cirrhosis & \multicolumn{2}{l}{ Control } & Liver cirrhosis & Control & Liver cirrhosis \\
\hline Ile & $73.3 \pm 12.8$ & $49.4 \pm 12.9^{* * * *}$ & $28.7 \pm 6.3$ & $15.6 \pm 6.7^{* * * *}$ & $0.607 \pm 0.076^{\circ}$ & $0.688 \pm 0.131^{\circ}$ \\
Leu & $127.8 \pm 26.4$ & $86.0 \pm 22.9^{* * * *}$ & $55.4 \pm 10.3$ & $30.3 \pm 11.5^{* * * *}$ & $0.554 \pm 0.066^{\circ}$ & $0.649 \pm 0.114^{\circ}$ \\
Val & $247.3 \pm 42.7$ & $171.4 \pm 37.4 * * * *$ & $168.0 \pm 29.6$ & $119.2 \pm 33.4^{* * * *}$ & $0.382 \pm 0.144$ & $0.338 \pm 0.064$ \\
Tyr & $55.8 \pm 10.1$ & $156.0 \pm 44.1^{* * * *}$ & $29.7 \pm 6.5$ & $122.9 \pm 44.4^{* * * *}$ & $0.472 \pm 0.045$ & $0.258 \pm 0.097^{* * * *}$ \\
Phe & $55.1 \pm 8.3$ & $83.7 \pm 18.5^{* * * *}$ & $35.3 \pm 4.8$ & $59.3 \pm 14.5^{* * * *}$ & $0.367 \pm 0.059$ & $0.295 \pm 0.102^{*}$ \\
Trp & $53.5 \pm 12.9$ & $54.9 \pm 8.9$ & $41.4 \pm 12.3$ & $51.3 \pm 10.3^{* *}$ & $0.279 \pm 0.123$ & $0.061 \pm 0.179^{* * * *}$ \\
\hline
\end{tabular}

Decrease ratio: maximum decrease during 3 hours after load/initial concentration.

Values: Mean $\pm 1 \mathrm{SD}$. Student's t-test was applied, assuming a normal distribution of these values:in samples tested.

Significant difference from control ${ }^{*} p<0.05,{ }^{* *} p<0.02,{ }^{* *} p<0.01$, **** $p<0.001$. Significant difference from valine ${ }^{\circ} p$ $<0.001$

Changes in $t-\operatorname{Trp} / B C A A+A A A$ and $B C A A / A A A$ during oral glucose tolerance test

Table 2 shows the ratio of $\mathrm{t}$-Trp/BCAA + AAA in a fasting state and 3 hours after loading in patients with liver cirrhosis and in controls; the ratio after

Tab. 2. Change of $t-T r p / B C A A+A A A$ of plasma during $100 \mathrm{~g}$ oral glucose tolerance test.

\begin{tabular}{llll}
\hline & Before & 3 hours & Net increase \\
\hline Control & $0.096 \pm 0.024$ & $0.129 \pm 0.033^{\circ}$ & $0.031 \pm 0.021$ \\
$\begin{array}{l}\text { Liver } \\
\text { cir- } \\
\text { rhosis }\end{array}$ & $0.103 \pm 0.019$ & $0.158 \pm 0.031^{* \circ}$ & $0.055 \pm 0.026^{* *}$ \\
\hline
\end{tabular}

Net increase: $t-\operatorname{Trp} / \mathrm{BCAA}+\mathrm{AAA}$ at 3 hours after load minus that of fasted states.

Significant difference from control: ${ }^{*} \mathrm{p}<0.05,{ }^{* *} \mathrm{p}<0.02$, Significant difference from the initial value: ${ }^{\circ} p<0.001$. loading was elevated significantly in both cases, and the net increase for liver cirrhosis $(0.055)$ was higher $(p<0.02)$ than that for controls $(0.031)$. The change of the BCAA/AAA ratio by glucose loading is shown in table 3. It decreased in liver cirrhosis but did not change in controls. The relationship between BCAA/ AAA (fasting state) and indocyanine green test was examined (fig. 4), and a good correlation was found $(\mathrm{r}=-0.8045, \mathrm{y}=-0.077 \mathrm{x}+4.24, \mathrm{p}<0.01, \mathrm{n}=$ 33).

Tab. 3. Change of BCAA/AAA of plasma during oral glucose tolerance test.

\begin{tabular}{lll}
\hline & Before & 3 hours after load \\
\hline Control & $3.9 \pm 0.6$ & $3.9 \pm 0.6$ \\
Liver cirrhosis & $1.4 \pm 0.6$ & $1.0 \pm 0.6^{*}$ \\
\hline
\end{tabular}

Significant difference from the initial value, $* \mathrm{p}<0.1$. 


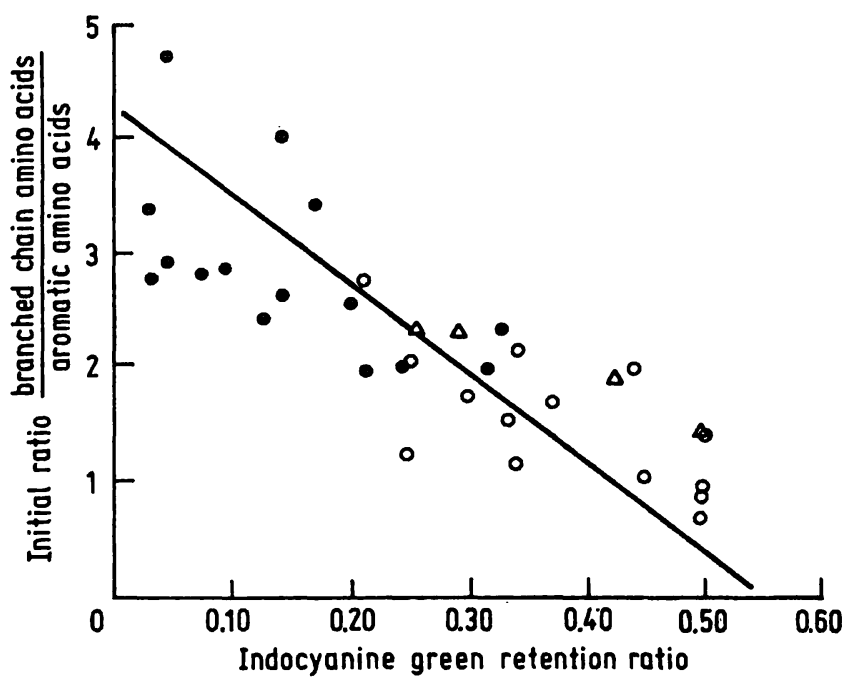

Fig. 4. Relation between branched chain amino acids (BCAA)/ aromatic amino acids (AAA) ratio of plasma before loading of glucose and the retention ratio of indocyanine green at $15 \mathrm{~min}$ after injection in patients with liver diseases. chronic hepatitis, $\Delta$ liver cancer, $O$ liver cirrhosis. $y=-0.077 x+4.24, r=-0.8045$, $\mathrm{p}<0.01(\mathrm{n}=33)$.

\section{Discussion}

We loaded $100 \mathrm{~g}$ of glucose orally to patients with liver cirrhosis and controls, and changes of plasma amino acids during the oral glucose tolerance test were examined. After the oral glucose tolerance test, the ratio $t-\operatorname{Trp} / \mathrm{BCAA}+\mathrm{AAA}$ was observed to increase in patients with liver cirrhosis and controls and moreover its net increase was higher $(\mathrm{p}<0.02)$ in liver cirrhosis than in controls. The ratio, branched chain amino acids/aromatic amino acids (BCAA/ AAA), was found to decrease slightly in all patients with liver cirrhosis at 3 hours after loading, and the same tendency was observed in patients with chronic hepatitis and liver cancer (data not shown).

Marchesini et al. (9) performed the same experiments and observed an increase in the ratio plasma insulin/ glucagon, thereby improving the catabolic state. They emphasized that $\mathrm{f}$-Trp/BCAA + AAA decreased in patients with liver cirrhosis after the oral glucose tolerance test, and concluded that the oral glucose tolerance test was more effective in patients with liver cirrhosis than in controls in bringing about recovery from hepatic encephalopathy. But the authors had fractionated the free tryptophan by centrifugation without $\mathrm{pH}$ control, and the tryptophan determination was carried out by the Denckla \& Dewey method (10) which has been reported to have wide margin of error (11). Although we did not measure fTrp/BCAA + AAA in the present study, Fernstrom \& Wurtman (1) reported that plasma t-Trp/BCAA + AAA shows a strong positive correlation with brain tryptophan concentrations among healthy rats after consumption of carbohydrates, but that plasma free tryptophan is not correlated with brain tryptophan.

In our previous study (5), no significant difference in plasma free tryptophan concentration was observed between liver cirrhosis patients with or without hepatic encephalopathy, and plasma free tryptophan was significantly higher in liver cirrhosis with bleeding tendency than in without bleeding tendency.

Cummings et al. (12) showed tryptophan and 5-hydroxyindole acetic acid in brain to be significantly elevated in portocaval anastomosed rats as compared with control rats and that administration of branched chain amino acids caused brain indoles to decrease toward normal levels. This result may reasonably explain why the administration of branched chain amino acids lowered the ratio of $\mathrm{t}-\mathrm{Trp} / \mathrm{BCAA}+\mathrm{AAA}$ in plasma, accompanied by decreased uptake of tryptophan into brain. By taking account of these results and our present study, oral glucose tolerance test in cases of liver cirrhosis might increase the risk of hepatic encephalopathy. Lowering the BCAA/ AAA by oral glucose tolerance test has an opposite effect to that of infusing special amino acids enriched with branched chain amino acids to assist recovery from hepatic encephalopathy. Although BCAA/AAA did not necessarily correlate to consciousness levels, its value usually fell with the progress of hepatic failure.

Morgan et al. (13) asserted that the BCAA/AAA ratio showed a good correlation with the histologically judged severity of liver diseases. In the present study a strong negative correlation between BCAA/ AAA and indocyanine green retention ratio was recognized (fig. 4). If we assume that BCAA/AAA is negatively correlated with the permeability of the blood brain barrier, and indocyanine green retention ratio correlates inversely with liver function, patients whose BCAA/AAA is low would face an increased risk of hepatic encephalopathy, due to the increase in uptake of tryptophan, aromatic amino acids and other substances related to hepatic encephalopathy.

Considering the net increase of $t-\operatorname{Trp} / \mathrm{BCAA}+\mathrm{AAA}$ during oral glucose tolerance test, which was 0.031 in controls and 0.055 in patients with liver cirrhosis, entry of tryptophan into the brain would be elevated in patients with liver cirrhosis. The increased uptake of tryptophan by the brain might result in the brain becoming oedematous, followed by disturbances to the permeability of the blood brain barrier. In fact Hirayama reported that an oral tryptophan load evoked drowsiness, dizziness and nausea in patients with liver cirrhosis more severely than in controls, 
suggesting that brain tryptophan is increased much more readily in patients with liver cirrhosis (3). During our study, almost all subjects complained of drowsiness or even slept. Närvänen (14) reported that some healthy volunteers showed tiredness and loss of concentration after oral glucose tolerance test, possibly because the increase of serotonin in whole blood resulted in its decrease in the neurons.

Generally, much attention has been paid to protein diets for protection against hepatic encephalopathy.

\section{References}

1. Fernstrom, J. D. \& Wurtman, R. J. (1972) Science 178, 414-416.

2. Ogihara, K., Mozai, T. \& Hirai, S. (1966) New Engl. J. Med. 275, 1255-1256.

3. Hirayama, C. (1971) Clin. Chim. Acta 32, 191-197.

4. Fernstrom, J. D., Wurtmann, R. J., Wiklund, B. H., Rand, W. M., Munro, H. N. \& Davidson, C. S. (1979) Am. J. Clin. Nutr.' 32, 1912-1933.

5. Hijikata, Y., Hara, K., Shiozaki, Y., Murata, K. \& Sameshima, Y. (1984) J. Clin. Chem. Clin. Biochem. 22, 291-299.

6. Muller, W. A., Faloona, G. R. \& Unger, R. H. (1971) New Engl. J. Med. 285, 1450-1454.

7. Hara, K., Uenishi, E., Ishii, D., Egawa, H., Yasuhara, A. \& Murata, K. (1981) Japan J. Clin. Chem. 10, 267-273.
However attention must also be paid to carbohydrate diets. The possibility of hepatic encephalopathy might be enhanced by continuously giving carbohydrates to patients with liver cirrhosis without branched chain amino acid supplements.

$$
\text { . }
$$

\section{Acknowledgment}

We are indebted to Dr. T. Mizuno of Kansai Medical University for referring patients for study.

8. Hijikata, Y., Hara, K., Egawa, H., Mizuno, T., Shiozaki, Y., Murata, K. \& Sameshima, Y. (1981) Anal. Biochem. $118,10-16$.

9. Marchesini, G., Forlani, G., Angiolini, A., Zoli, M., Scolari, M. P., Bianchi, F. B. \& Pisi, E. (1979) Diabete \& Metabolisme 5, 135-139.

10. Denckla, W. D. \& Dewey, H. K. (1967) J. Lab. Clin. Med. $69,160-169$.

11. Bloxam, D. L. \& Warren, W. H. (1974) Anal. Biochem. 60, $621-625$.

12. Cummings, M. G., Soeters, P. B., James, J. H., Keane, J. M. \& Fischer, J. E. (1976) J. Neurochem. 27, 501-509.

13. Morgan, M. Y., Milson, J. P. \& Sherock, S. (1978) Gut 19, 1068-1073.

14. Närvänen, S. (1983) Șcand. J. Clin. Lab. Invest. 43, Suppl. $167,1-47$.

Yasuyo Hijikata, Yasuko Shiozaki,

Yoshiko Sameshima

The 3rd Department of Internal Medicine

Kansai Medical University

1 Fumisonocho, Moriguchi, Osaka 570

Japan 